\title{
Potencial de índices urbanísticos como indicadores da qualidade térmica do ambiente urbano
}

\author{
Potentiality of urban indexes as indicators of the thermal quality of the urban air
}

\author{
Juliano Souza Vasconcelos ${ }^{1 *}$, Léa Cristina Lucas de Souza²
}

口-

\begin{abstract}
RESUMO
A qualidade térmica do ambiente urbano é um dos problemas enfrentados pelas cidades atualmente. A forma de ocupação urbana altera o balanço de energia nas cidades, provocando frequentemente um aquecimento do ar nas camadas intraurbanas e criando microclimas variados. No entanto, mapear os microclimas urbanos possibilitando apoio à tomada de decisões de planejamento urbano é uma tarefa complexa e de longo prazo. Procurando demonstrar as potencialidades térmicas oferecidas por alguns índices urbanísticos usualmente aplicados por órgãos decisores, este artigo buscou verificar a influência dos coeficientes de ocupação, de aproveitamento e de cobertura vegetal sobre a temperatura do ar em microclimas urbanos. Em uma fração urbana de ocupação consolidada, foram realizadas medições em campo, que serviram de base para a validação de um modelo computacional de simulação do ambiente térmico urbano. Posteriormente foram feitas simulações com diferentes índices urbanísticos e desenvolvidos mapas térmicos. Os resultados apontaram que os coeficientes estudados devem ser mais explorados termicamente, principalmente se considerado o coeficiente de cobertura vegetal, cuja alteração de valores pode levar a diferenças mais significativas na temperatura do ar.
\end{abstract}

Palavras-chave: clima urbano; microclima; índice urbanístico; simulação climática.

\begin{abstract}
The thermal quality of the urban environment is nowadays one of the problems faced by cities. The form of urban occupation changes the energy balance within cities, often causing a warming of the air in the urban canopy layer and generating a variety of microclimates. Mapping the urban microclimates to enable the support of decisions in urban planning is a complex and long-term task. Aiming to demonstrate the thermal potentiality offered by some urban indexes usually applied by decision-makers, this paper seeks to investigate the influence of the coefficient of occupation, the floor space index and the vegetation cover index on the air temperature of urban microclimates. At an urban zone already consolidated, field measurements were performed, allowing the creation of a basis for the validation of a computational model applied for simulating the urban thermal environment. Finally, different indexes were simulated, and thermal maps were developed. The results showed that the thermal potential of the studied coefficients should be further explored, especially considering the coefficient of vegetation, whose range of values can lead to more significant differences in the air temperature.
\end{abstract}

Keywords: urban climate; microclimate; urban indexes; climatic simulation.

\section{INTRODUÇÃO}

A alteração do ambiente térmico é uma das consequências da urbanização, porém poucas são as ferramentas legislativas urbanas que permitem rebater a questão térmica no planejamento da cidade e no desenho urbano. Como comentam Melo e Barbirato (2011), o modelo de urbanização brasileiro caracteriza-se pela expansão e segregação espacial da malha urbana. Somados a isso, os instrumentos responsáveis pela ordenação do solo nem sempre contribuem para assegurar o conforto térmico urbano.
Desde as primeiras décadas do século XIX, são realizados estudos sistemáticos para diagnosticar os efeitos da urbanização no clima das cidades (CALLEJAS et al., 2011) em busca da minimização desses efeitos. Os estudos de Oke (1982) são exemplos referenciais nessa abordagem. Partindo inicialmente da relação entre o aumento da temperatura do ar e a população, as pesquisas evoluíram para o enfoque do fluxo de calor e balanço energético. No Brasil, a partir de Monteiro (1976), muitos trabalhos surgiram envolvendo a temática do clima urbano e a interferência de todos os fatores que se processam sobre a

1 Universidade Federal de São Carlos (UFSCar) - São Carlos (SP), Brasil.

${ }^{2}$ Professora/orientadora do Programa de Pós-Graduação em Engenharia Urbana da UFSCar - São Carlos (SP), Brasil.

*Autor correspondente: julianojsv@gmail.com

Recebido: 07/05/2014 - Aceito: 21/03/2017 - Reg. ABES: 134577 
camada limite urbana (acima do topo das edificações) e que alteram o clima na escala local.

A qualidade de vida em áreas urbanas depende das condições climáticas e microclimáticas proporcionadas pelos espaços da cidade e, segundo Katzschner e Thorsson (2009), a apreensão microclimática influi na frequência de uso dos espaços em diferentes épocas e horários. Assim, o ambiente térmico dos espaços urbanos merece especial atenção, principalmente se considerado que, conforme apontam Oha et al. (2012), os edifícios podem causar mudanças microclimáticas em escalas de alguns quilômetros quadrados. Em consequência, o conforto térmico no exterior e no interior do prédio é alterado, de forma que, segundo Johansson (2006), influi no uso de energia para o aquecimento e arrefecimento e na dispersão de poluentes.

Diversos são os fatores de ocupação que interagem sobre o ambiente térmico urbano. Para Unger e Poncráz (2008), a geometria da superfície urbana é determinante da distribuição de temperatura dentro de uma cidade. Essa ideia é complementada também por Johansson (2006), ao demonstrar que o acesso solar é maior em ruas largas e espaços abertos e que o desenho mais compacto do espaço urbano pode colaborar no sombreamento das áreas de pedestres, favorecendo as condições térmicas de verão.

Uma forma de se fornecer subsídios para que essas questões possam ser efetivamente tratadas no planejamento das cidades é conferir a importância térmica aos elementos que hoje são aplicados por órgãos gestores e decisores. Nesse sentido, índices urbanísticos revelam-se como ferramentas potencialmente promissoras. Duarte (2010) estudou relações térmicas de índices urbanísticos em Cuiabá e São Paulo e encontrou influências no aumento de temperaturas nos dois locais, sendo essa relação de módulo positivo para áreas construídas e negativo para áreas arborizadas. Esse comportamento é confirmado por Rocha et al. (2011), ao verificarem que a presença da vegetação e a permeabilidade do solo contribuem na diminuição da temperatura do ar noturno, enquanto áreas com maior ocupação e mais pavimentação levam ao aquecimento do entorno. Souza (2010) também demonstra os efeitos da vegetação, indicando que as áreas arborizadas possuem vantagens, como equilíbrio do balanço térmico e qualificação térmica.

Apesar dos estudos demonstrarem indícios dessas relações, ainda faltam dados que permitam estabelecer claramente as interações entre os índices urbanísticos e a temperatura do ar. Para auxiliar nessa tarefa, modelos de simulações são aplicados em diversas pesquisas, pois permitem a criação de cenários reais e hipotéticos, em curto espaço de tempo. Os modelos de simulação para o clima urbano podem ser divididos em três tipos: numérico, empírico e físico (NAKATA \& SOUZA, 2013).

Entre os modelos computacionais, um dos que mais têm sido aplicados atualmente na escala do desenho urbano é o software ENVI-met. Ele foi desenvolvido por Bruse (2003) e para Huttner et al. (2008), trata-se de um modelo tridimensional de microclima não hidrostático que inclui: modelo simples tridimensional do solo; um modelo de transferência radiativa; e um modelo de vegetação. Carfan et al. (2009) mostraram que esse modelo simula de forma satisfatória o comportamento da camada limite urbana (camada de ar adjacente à superfície terrestre), enquanto Minella et al. (2011) afirmam que é possível utilizá-lo para previsão das condições dentro do cânion urbano.

Com base nessas considerações, essa pesquisa buscou verificar a importância térmica de alguns índices urbanísticos, tais como o coeficiente de ocupação, de aproveitamento e de cobertura vegetal, para o estudo da temperatura do ar na camada intraurbana. Para isso explora as potencialidades oferecidas pelo modelo ENVI-met.

\section{MATERIAIS E MÉTODOS}

Os procedimentos metodológicos básicos adotados constituem-se em etapa de levantamentos físicos da fração urbana real, medições e análises das condições térmicas desse local e, posteriormente, simulação e criação de cenários futuros, aplicando-se o programa computacional ENVI-met.

\section{Área de estudo}

Uma fração urbana da cidade de São Carlos, foi utilizada como elemento de referência para que dados reais pudessem ser a base da análise proposta. Esse município possui uma população total de cerca de 222 mil habitantes (IBGE, 2010) e está localizado na região central do estado de São Paulo. Suas coordenadas geográficas correspondem à latitude $22^{\circ} 01^{\prime} 06.10^{\prime \prime}$ sul e à longitude 47053'28.09" oeste (PREFEITURA MUNICIPAL DE SÃO CARLOS, 2012). Está implantada entre as altitudes de 560 e 1.000 metros, com média de $856 \mathrm{~m}$ de altitude (PREFEITURA MUNICIPAL DE SÃO CARLOS, 2012), apresentando temperatura do ar média anual de $19,6^{\circ} \mathrm{C}$.

Nesse contexto, a fração de estudo selecionada encontra-se em situação topográfica que corresponde ao plano mais alto da cidade, com ocupação de uso misto (com residências e prédios comerciais). Dentro dessa área foram fixados pontos de observação e caracterização para um exame das condições microclimáticas urbanas. Essas observações foram feitas a partir de um total de quatro pontos de coleta de dados (A, B, C e D) intraurbanos e um ponto de observação na altura do topo das edificações (TE), correspondente ao topo da camada intraurbana. Esses podem ser observados na Figura 1. A posição dos pontos procurou garantir o mínimo de diferenças de altitudes e foi dependente da disponibilidade e autorização de moradores das residências para a instalação de equipamentos.

\section{Levantamentos físicos da fração escolhida}

Com base na seleção da fração urbana anteriormente descrita, foram caracterizados seus índices urbanísticos por meio de levantamentos com mapas, imagens e visitas in loco. Os índices urbanísticos aqui considerados são aqueles estabelecidos pelo Plano Diretor, que determina o uso da ocupação dos solos, sendo eles: o de coeficiente de ocupação, o de aproveitamento e o de cobertura vegetal (aqui denominado coeficiente vegetal urbano).

Com base no Plano Diretor de São Carlos (SÃO CARLOS, 2005), o coeficiente de ocupação (CO) é a razão entre a área de projeção da 
edificação e a área do lote. O coeficiente de aproveitamento (CA) é a relação entre a área edificada e a área do terreno. O coeficiente vegetal urbano é a relação entre a área vegetada e o lote. Para os pontos de observação, esses cálculos foram efetuados a partir da estimativa das alturas dos edifícios, de forma a considerar $3 \mathrm{~m}$ por pavimento, e com base naqueles índices dentro de um raio de abrangência de $50 \mathrm{~m}$.

\section{Levantamento das condições térmicas}

Procurou-se realizar as medições em período sujeito a condições de baixa umidade na região pesquisada. Essa situação é indicada para a verificação da maior influência da estrutura urbana sobre as condições térmicas, conforme apontado por Oke (1982).

Durante período seco, de 13 de julho a 14 de agosto de 2012, nos pontos de coleta urbanos foram realizadas medições de dados térmicos, correspondentes à temperatura do ar e à umidade relativa do ar, enquanto foram registrados dados climáticos rurais disponibilizados pela estação meteorológica do Instituto Nacional de Meteorologia (INMET). Para as medições intraurbanas, foram instalados equipamentos nos quatro pontos de coleta A, B, C e D (Figura 1).
Dentro desse período, foram identificadas janelas de tempo (sem nuvens) que melhor representassem o período seco, e para isso observaram-se as cartas sinóticas e os mapas de satélites, acessados pelo site do Instituto Nacional de Pesquisas Espaciais (INPE). Assim sendo, a campanha de medições gerou duas janelas de tempo. Os seguintes períodos correspondem, portanto, aos conjuntos de dados que compuseram o estudo em 2012: de 18 a 21 de julho e de 6 a 12 de agosto.

\section{Validação, simulação e criação de cenários aplicando o simulador ENVI-met}

A primeira etapa da simulação das condições térmicas da fração urbana estudada visou verificar a compatibilidade dos dados reais e simulados com o auxílio do modelo computacional ENVI-met. Com isso, buscou-se obter uma validação do modelo de forma a permitir a criação de cenários para a análise da influência dos coeficientes estudados sobre as condições térmicas microclimáticas.

As simulações foram realizadas para as condições médias determinadas para o período seco anteriormente caracterizado.

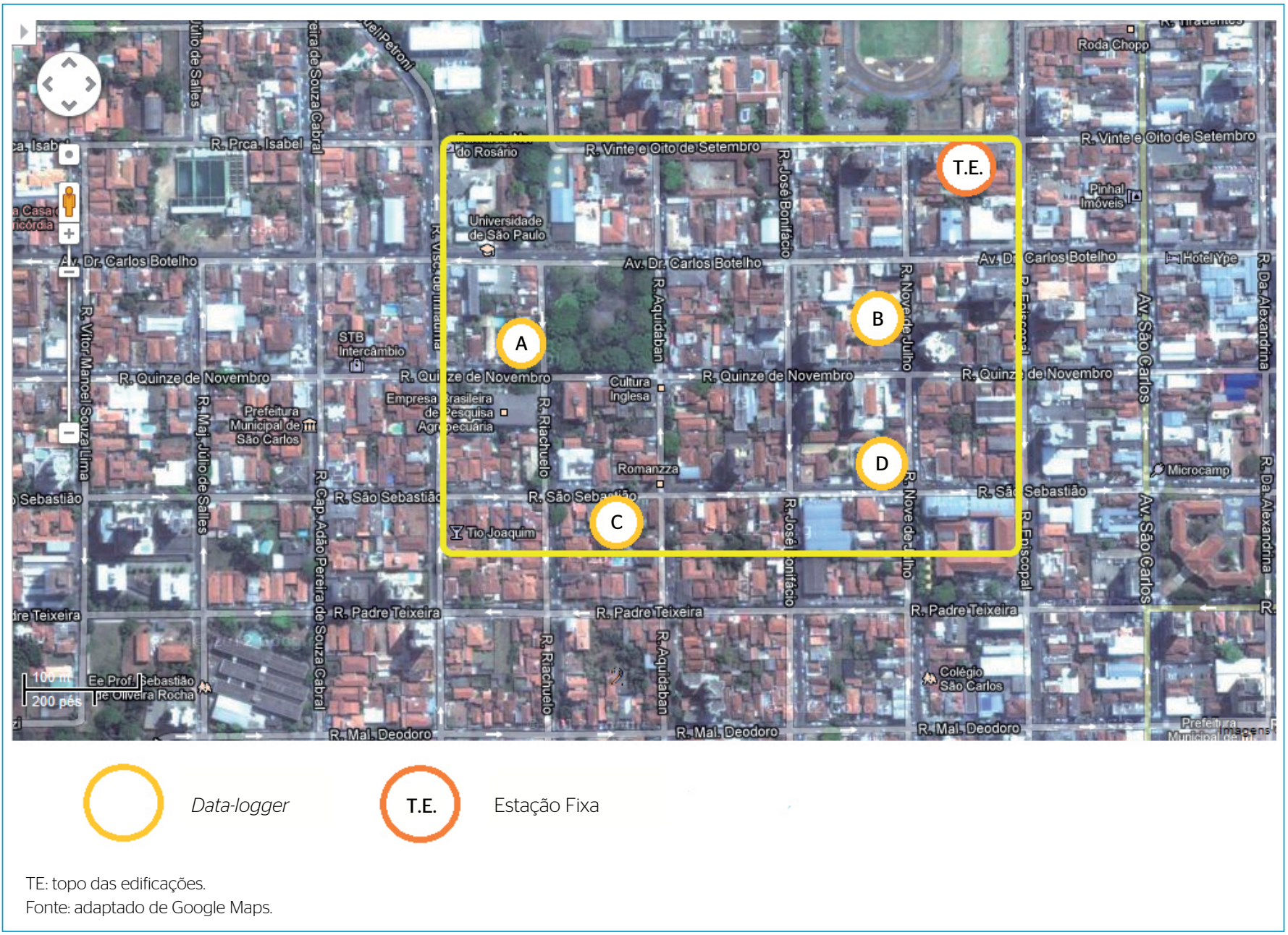

Figura 1 - Localização dos pontos de observação da primeira etapa. 
Para os cenários hipotéticos, foram promovidas alterações nos coeficientes urbanísticos, de forma que fossem simuladas situações de crescimento construtivo e/ou de áreas de vegetação urbana. Esses cenários futuros foram desenvolvidos com base no plano diretor para a área de estudo, permitindo identificar o impacto dessas alterações no ambiente térmico urbano.

Com o propósito de simular um cenário hipotético com os coeficientes máximos para edificações propostos pelo Plano Diretor de São Carlos, adotou-se o CO de 0,7 e o CA de 1,4. A referência para esses cálculos foi o mesmo ponto de coleta dos dados climatológicos reais. O critério de adensamento respeitou as construções dos edifícios originais já existentes e previu o aumento do espaço construído das residências, respeitando os locais verdes (com cobertura vegetal urbana).

Quanto à proporção da grade de representação da área na interface gráfica do modelo, obteve-se dx 3 , dy 3 e dz2, ou seja, cada 1 metro real representa 3 metros de comprimento x e largura y, e 2 metros de altura virtual, respeitando-se o padrão de entrada de dados exigido pelo programa. Os demais dados meteorológicos de entrada para o ENVImet foram obtidos pelo INMET. Especificamente para a obtenção dos dados climatológicos a $2.500 \mathrm{~m}$, que servem de entrada no ENVI-met, utilizaram-se dados obtidos da página eletrônica (http://weather.uwyo. edu/upperair/sounding.html) da University of Wyoming - Radiosonde. Como não existem números específicos da cidade de São Carlos disponíveis naquela base de dados, foi necessário interpolar dados registrados para três aeroportos, sendo eles: São Paulo, Minas Gerais e Brasília.

Respeitando os procedimentos indicados por Nakata (2010), os seguintes dados de entrada permitiram a inicialização da simulação:

- velocidade dos ventos a 10 metros $[\mathrm{m} / \mathrm{s}]$;

- direção dos ventos a (0 - norte, 90 - leste,180 - sul, e 270 — oeste);

- coeficiente de rugosidade da superfície;

- temperatura atmosférica inicial em Kelvin [K];

- umidade absoluta a 2.500 metros de altitude $\left[\mathrm{g}_{\text {agua }} / \mathrm{kg}_{\mathrm{ar}}\right]$;

- umidade relativa a 2 metros [\%].

A leitura dos resultados das simulações foi realizada por meio da aplicação da interface Leonardo, disponível no próprio simulador ENVI-Met.

As condições da construção dos mapas para a simulação foram divididas em situação real, cenário adensado e cenário arborizado com edificações reais.

\section{Análise para extração dos resultados}

Após a validação, foi determinado o horário de menor diferença entre os dados reais e os simulados. Esse horário tornou-se base de análise para que fossem relacionadas as médias das temperaturas por quadra e os coeficientes urbanísticos.

Inicialmente realizou-se uma análise geral da área, em função da temperatura do ar. Posteriormente, foram analisados os pontos iniciais de observação dentro do contexto da situação real simulada, para serem apontadas as tendências de cada um deles. Por fim, aplicando-se a técnica de regressão múltipla, foi desenvolvido um modelo para que fosse possível isolar a influência de cada um dos coeficientes estudados sobre a condição térmica do local.

\section{Resultados e discussão}

A partir dos pontos de observação A, B, C e D, foram efetuadas as caracterizações de índices urbanísticos, em relação ao raio de abrangência de $50 \mathrm{~m}$ a partir dos pontos de coleta (Tabela 1 ).

No ponto A encontram-se os menores índices de ocupação, assim como maior cobertura vegetal e menor coeficiente de aproveitamento. Os pontos $\mathrm{B}, \mathrm{C}$ e D indicam maiores $\mathrm{CO}$ e $\mathrm{CA}$ e menor presença de coeficiente de vegetação urbana (CVU). Entre esses últimos, o ponto $\mathrm{B}$ apresenta maior CA e CO similar à do ponto $\mathrm{D}$.

\section{Caracterização térmica}

Para cada um dos pontos de medição utilizados, faz-se a validação, comparando-se dados de temperaturas simuladas com as médias das janelas de tempo de julho e de agosto.

De acordo com os testes realizados por Nakata (2010), a curva de melhor aproximação entre dados reais e simulados é aquela que representa os cálculos realizados para a sexta iteração de dados. Essa foi também a curva aqui considerada para que se verificassem as diferenças entre dados reais e simulados. A partir dela puderam ser identificados os horários de maior precisão das simulações e desenvolvimento das análises.

As Tabelas 2 e 3 apontam os valores para os erros médios diários, as temperaturas máximas e mínimas nos períodos diário, diurno e noturno, com destaque para o horário em que ocorreu a melhor aproximação entre os dados medidos e simulados para a condição real de índices urbanísticos.

Em função dos resultados anteriormente apresentados, observa-se que a extração de informações a partir das simulações deve ser, preferencialmente, realizada entre 9 e 12 horas, para que os resultados possam ser mais fidedignos. Esse resultado coincide com as recomendações de Nakata (2010), que considera o horário de 10 horas aquele de melhor precisão de dados simulados em relação aos dados reais.

Considerando que os menores erros médios para as janelas de tempo analisadas foram atingidos pela simulação de julho, foi tomado o horário das 11 horas do mês de julho como referência para as análises.

Tabela 1 - Índices urbanísticos nos ponto de observação com base em 50 metro de raio.

\begin{tabular}{c|c|c|c} 
Ponto & CA & CO & CVU \\
\hline A & 0,26 & 0,20 & 0,35 \\
\hline B & 1,38 & 0,57 & 0,06 \\
\hline C & 0,62 & 0,49 & 0,10 \\
\hline D & 0,97 & 0,60 & 0,03 \\
\hline
\end{tabular}

CA: coeficiente de aproveitamento; $\mathrm{CO}$ : coeficiente de ocupação; $\mathrm{CVU}$ : cobertura vegetal urbana. 
Destaca-se ainda que, para julho, tanto 11 como 12 horas seriam períodos adequados de análise, porém o primeiro se aproxima mais daquele horário recomendado pela literatura e, por isso, foi aqui priorizado em relação ao segundo.

Tabela 2 - Temperaturas com os erros médios, máximas e mínimas, e o melhor horário para a simulação em julho.

\begin{tabular}{l|c|c|c|c}
\multirow{2}{*}{ Média } & \multicolumn{3}{|c|}{ Períodos } & \multirow{2}{*}{ Melhor horário } \\
\cline { 2 - 4 } & Diário & Diurno & Noturno & Ponto A \\
\hline Máximo & 2,4 & 2,8 & 1,9 & \\
\hline Mínimo & 3,9 & 3,9 & 3,5 & $11 \mathrm{~h}$ \\
\hline Média & 0,0 & 0,5 & 0,0 & Ponto B \\
\hline Máximo & 1,9 & 2,2 & 1,7 & \\
\hline Mínimo & 3,3 & 3,3 & 3,2 & $12 \mathrm{~h}$ \\
\hline Média & 0,3 & 0,3 & 0,3 & Ponto C \\
\hline Máximo & 2,2 & 2,5 & 2,2 & $12 \mathrm{~h}$ \\
\hline Mínimo & 3,9 & 3,9 & 3,6 & Ponto D \\
\hline Média & 2,1 & 0,1 & 0,3 & $11 \mathrm{~h}$ \\
\hline Máximo & 3,6 & 3,6 & 3,4 & \\
\hline Mínimo & 0,2 & 0,4 & 0,2 & \\
\hline
\end{tabular}

\section{Análise geral da temperatura do ar}

As Figuras 2, 3 e 4 apresentam os resultados para o mês de julho às 11 horas. Nelas, os pontos brancos destacados em cada esquina representam locais de leitura dos dados.

Tabela 3 - Temperaturas com os erros médios, máximas e mínimas, e o melhor horário para a simulação em agosto.

\begin{tabular}{l|c|c|c|c}
\multirow{2}{*}{ Média } & \multicolumn{3}{|c|}{ Periodos } & Melhor horário \\
\cline { 2 - 4 } & Diário & Diurno & Noturno & Ponto A \\
\hline Máximo & 2,7 & 3,7 & 1,7 & \\
\hline Mínimo & 6,8 & 6,8 & 4,4 & $10 \mathrm{~h}$ \\
\hline Média & 0,0 & 0,6 & 0,0 & Ponto B \\
\hline Máximo & 2,6 & 3,2 & 1,9 & $10 \mathrm{~h}$ \\
\hline Mínimo & 5,5 & 5,5 & 3,6 & Ponto C \\
\hline Média & 0,3 & 0,3 & 0,9 & $10 \mathrm{~h}$ \\
\hline Máximo & 2,4 & 3,3 & 1,6 & Ponto D \\
\hline Mínimo & 5,4 & 5,4 & 2,9 & \\
\hline Média & 0,2 & 0,2 & 0,5 & O9 h \\
\hline Máximo & 6,6 & 3,5 & 1,6 & \\
\hline Mínimo & 0,1 & 0,5 & 0,1 & \\
\hline & & & & \\
\hline
\end{tabular}

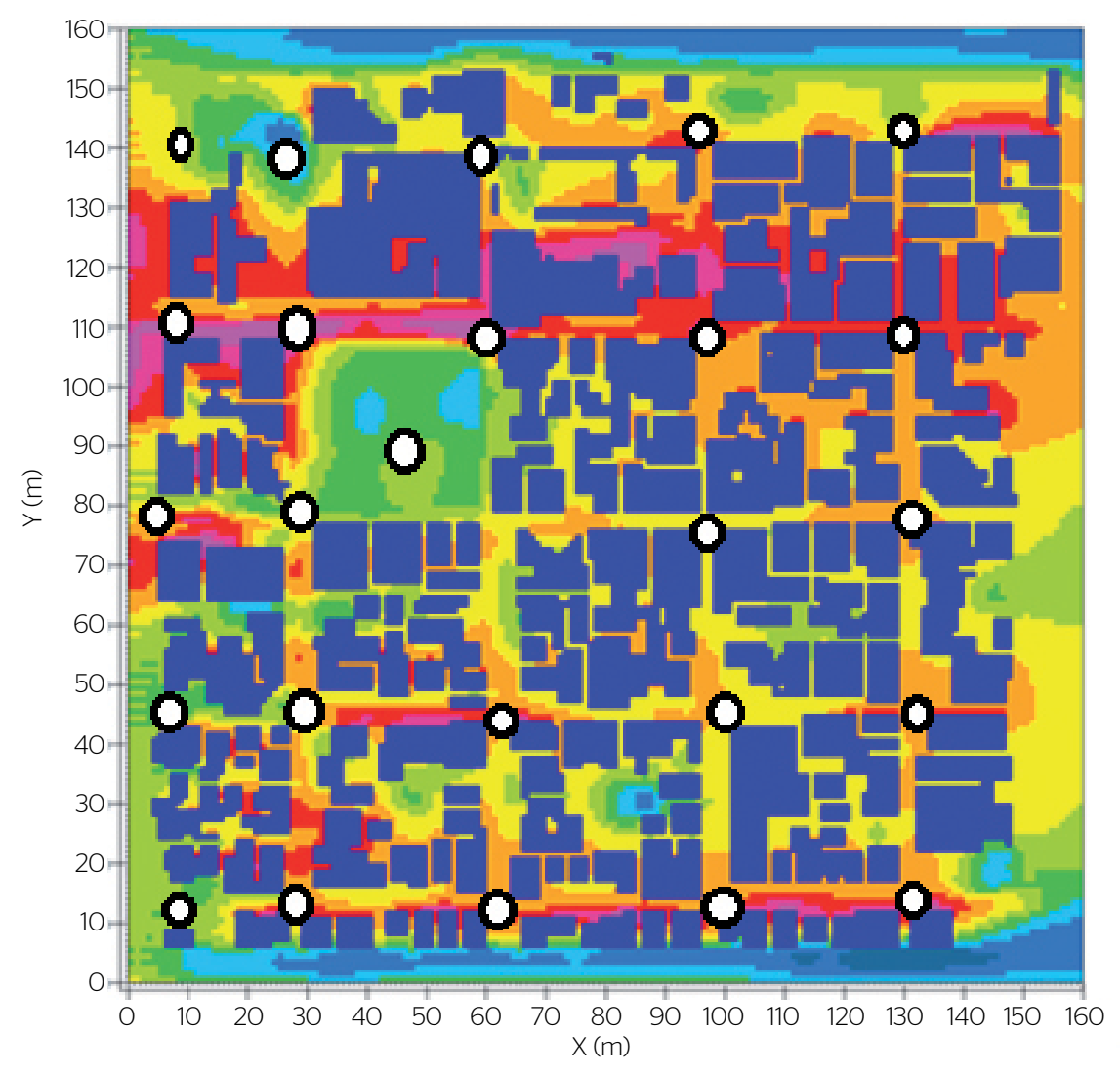

SimulSCarlos 11:00:00 23.07.2012
Temperatura $\left({ }^{\circ} \mathrm{C}\right)$

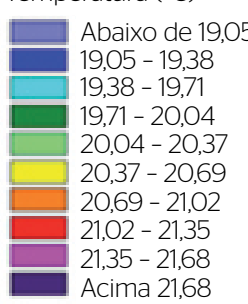


Observa-se, pelos mapas térmicos, que as quadras situadas a sudoeste tenderam a apresentar um ambiente térmico mais arrefecido do que as demais quadras da área de estudo. É também nessa parte da área de estudo que se concentram quadras que oferecem as edificações mais afastadas entre si e centros de quadras menos ocupados.

No geral, o cenário adensado apresenta um ambiente com frequência maior de temperaturas mais altas, distribuídas mais homogeneamente e, portanto, com menos pontos de contraste do que a situação real e o cenário arborizado.

A quadra em que se encontra a praça arborizada é notoriamente o local de destaque térmico em relação às demais. Em todos os cenários essa é a que se mantém mais resfriada, confirmando o potencial apresentado pela vegetação na mitigação do calor. Ressalta-se ainda que essa quadra não sofreu adensamento em nenhum dos cenários simulados.

Avaliando-se as diferenças médias de temperatura nos diversos pontos de leitura entre os cenários estudados, a Figura 5 permite estabelecer uma análise quantitativa complementar aos mapas térmicos.

Verificou-se uma elevação da temperatura média do ar de cerca de $0,21^{\circ} \mathrm{C}$ para julho, quando a situação atual é comparada ao cenário adensado. Ao comparar a situação atual com o cenário arborizado, são constatadas reduções nas temperaturas do ar de cerca de $0,88^{\circ} \mathrm{C}$. Quando examinadas as diferenças entre o cenário adensado e o arborizado, são encontrados valores da ordem de $1,09^{\circ} \mathrm{C}$ para julho.

Portanto, foi possível constatar um pequeno impacto de aquecimento sobre o ambiente térmico da área, provocado pelo adensamento. Por outro lado, houve um impacto de resfriamento significativo, quando a arborização foi intensificada, principalmente se considerada a comparação entre os cenários adensados e arborizado.

Destaca-se que a análise apenas pelos valores médios das diferenças térmicas por si só não é capaz de revelar a abrangência espacial desse aquecimento ou resfriamento provocados pelas alterações nos cenários. Para revelar essa espacialidade, além dos mapas térmicos gerados pelo ENVI-met, a visualização por quadras como unidades térmicas torna-se uma escala de mais rápida apreensão das informações — da mesma forma apontado por Mendonça et al. (2013) em um estudo acústico. Um exemplo dessa técnica pode ser averiguado pela observação das Figuras 6, 7 e 8, em que foram consideradas classes térmicas de algumas quadras pelas médias das temperaturas encontradas no seu entorno.

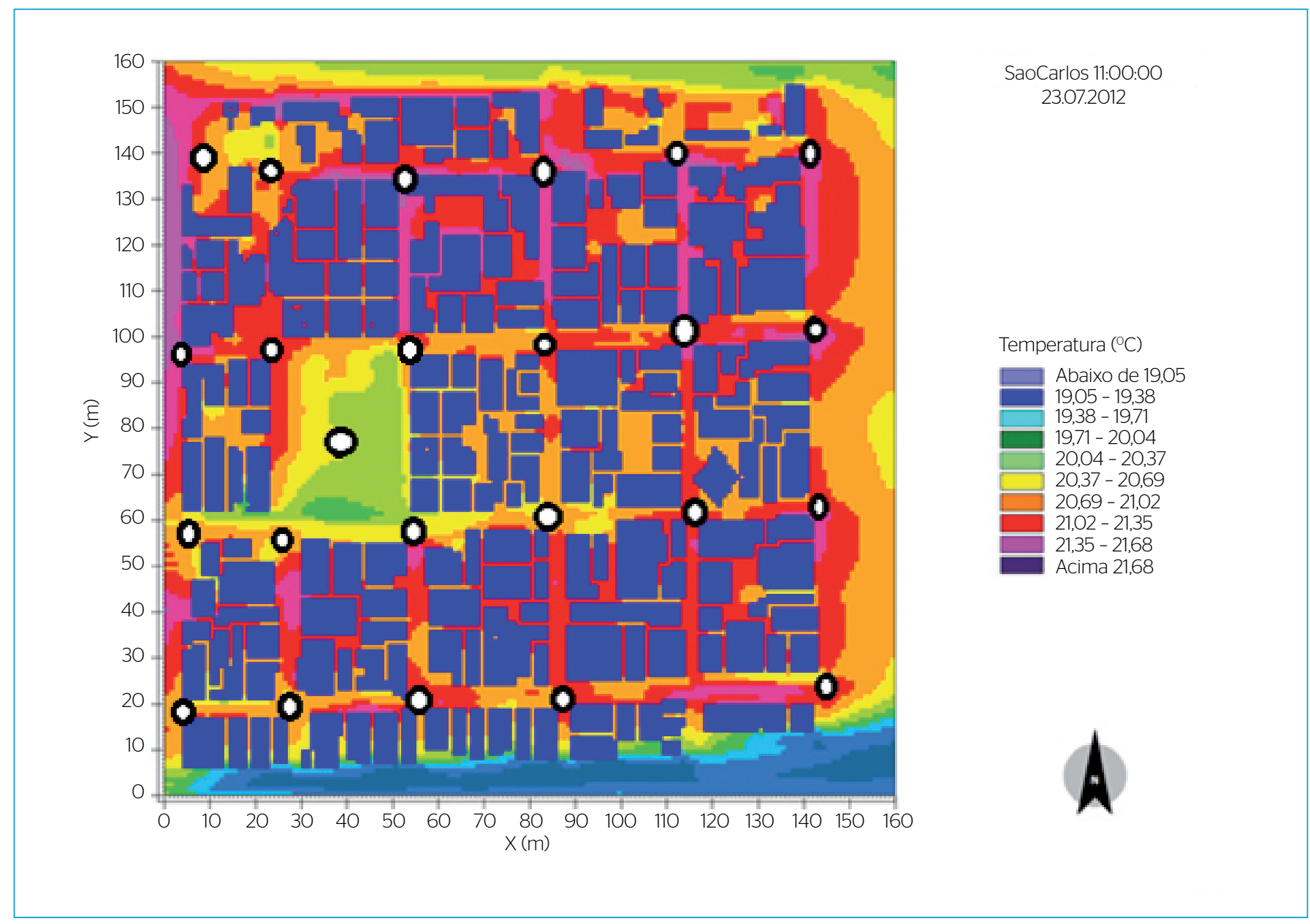

Figura 3 - Mapa térmico para o cenário adensado. 
Os mapas de classes térmicas de quadras urbanas indicam que um número significativo de quadras sofreu alterações, tanto pelo adensamento quanto pela arborização. Quando se compara a situação atual com o cenário adensado, a porcentagem de quadras acima de $21^{\circ} \mathrm{C}$ passa de 47 para $87 \%$ do total de quadras da área.

Em todos os cenários evidenciou-se o papel da praça como amenizador climático. Esse papel da vegetação é ainda mais significativo quando o cenário arborizado é observado. Nesse caso, 100\% das quadras passaram a apresentar temperaturas mais baixas do que $21^{\circ} \mathrm{C}$.

Apesar da pequena ordem de grandeza do aquecimento decorrente do adensamento promovido, apresentado na Figura 9, nele são examinados os percentuais de adensamento promovidos na área (aumento do CO) e as respostas térmicas médias obtidas em relação à situação real.

Pode-se assim observar que, guardadas as limitações do grau de aquecimento ocorrido, ainda é possível verificar que quanto maior o CO, maior é a diferença de temperatura do ar no cenário adensado em relação à situação real. Porém, é também importante destacar que o impacto de adensamento foi mais significativo entre 44 e $57 \%$ do que nas faixas acima de $57 \%$. Isso pode

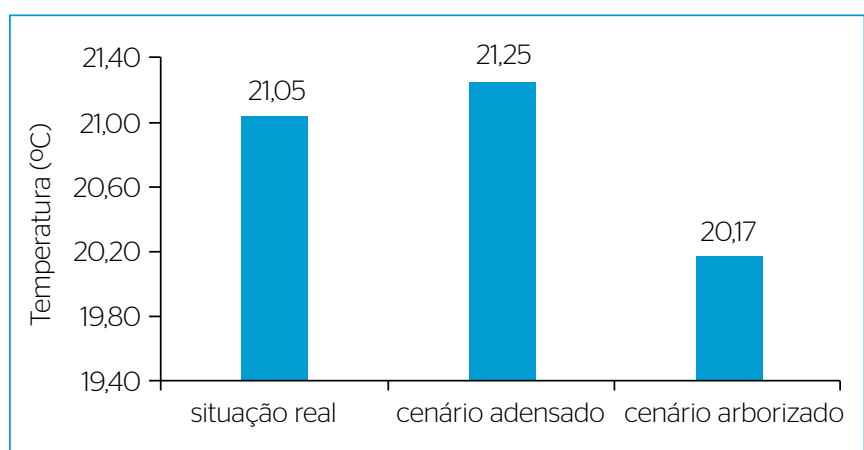

Figura 5 - Diferenças térmicas entre os cenários em julho.

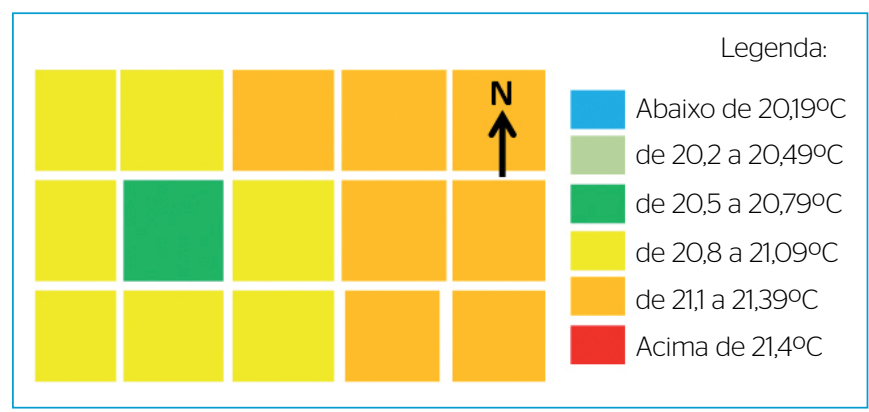

Figura 6 - Diferenças térmicas das quadras para a situação atual.

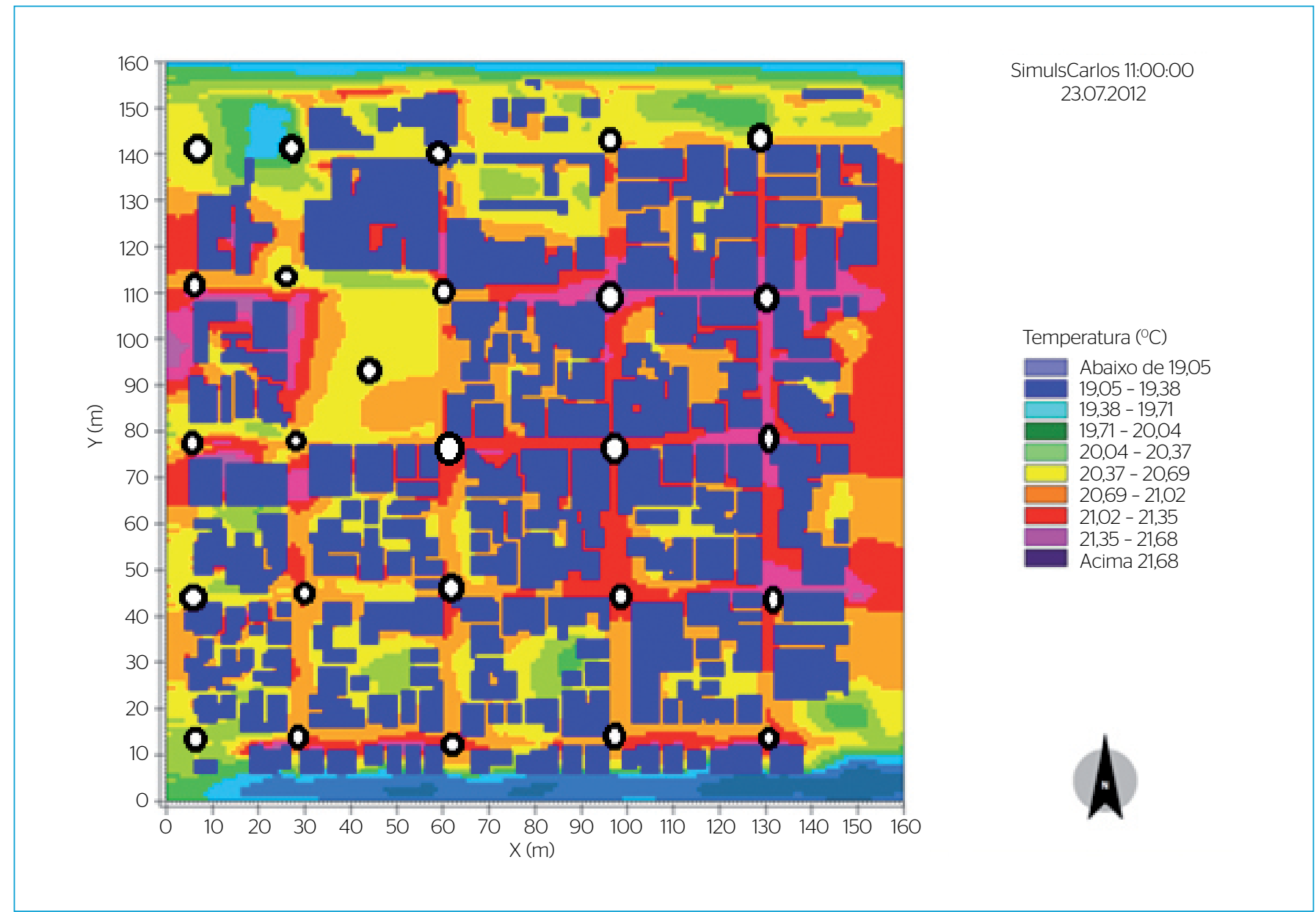

Figura 4 - Mapa térmico para o cenário arborizado com edificações reais. 
ser constatado pelas declividades apresentadas pela Figura 9. Inicialmente, entre 44 e $57 \%$, a curva apresenta um aclive maior do que as faixas seguintes, entre 57 e $86 \%$, pois essas últimas tendem a formar um patamar.

Essa observação indica que o impacto de um adensamento em uma quadra pouco ocupada é maior do que aquele em uma que já apresente ocupação mais significativa. Essa tendência para a mesma área de estudo já havia sido anteriormente apontada por Souza (1996), e pode ser facilmente explicada pelas características térmicas dos materiais de construção em relação ao solo natural. Os materiais de construção apresentam calor específico mais baixo do que as superfícies vegetais ou solos naturais e, portanto, elevam rapidamente a sua temperatura ao receberem a radiação solar.

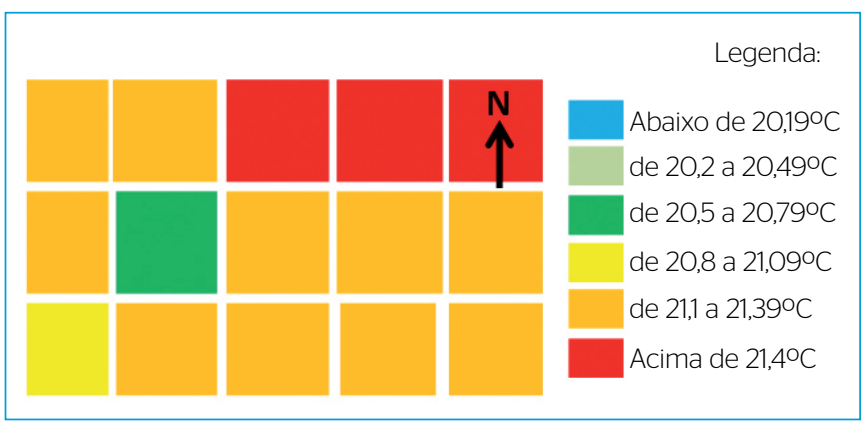

Figura 7 - Diferenças térmicas das quadras para o cenário adensado.

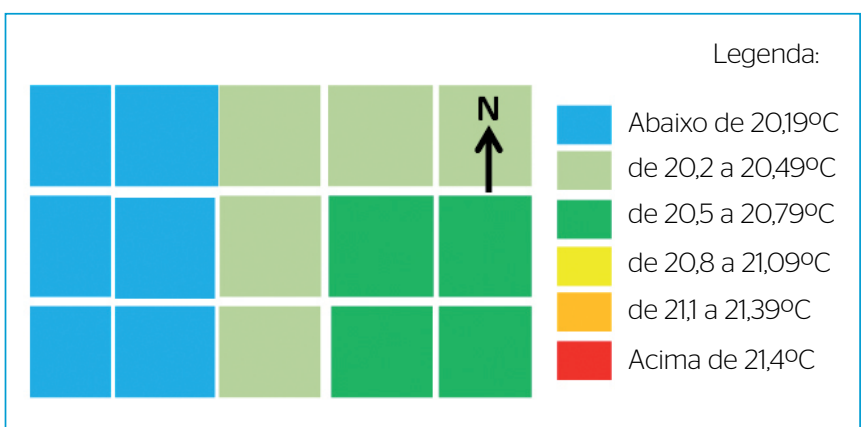

Figura 8 - Diferenças térmicas das quadras para o cenário arborizado.

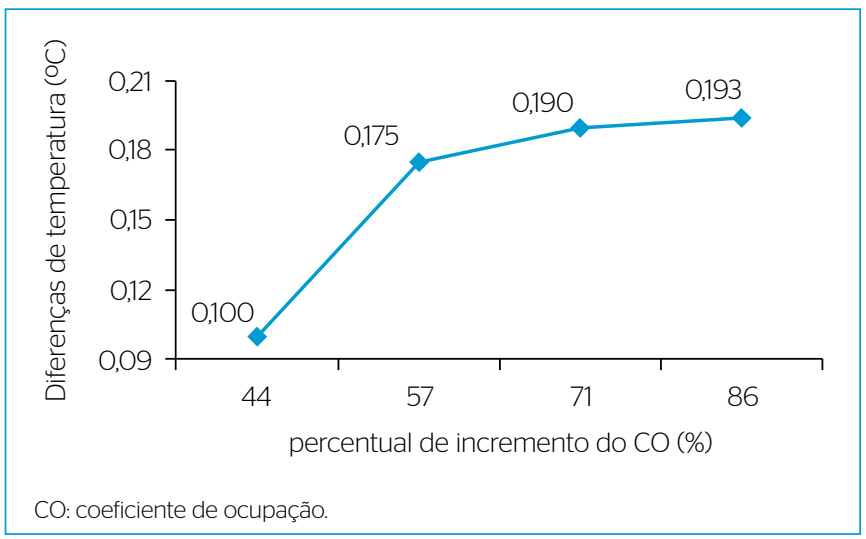

Figura 9 - Diferenças de temperaturas em função do aumento do coeficiente de ocupação.
Para análise da relação das diferenças da temperatura do ar com o percentual de incremento no índice de aproveitamento, observa-se a Figura 10.

Nesse caso, observou-se que a partir da faixa de incremento entre 60 e $80 \%$ acima do CA existente, parece haver uma tendência de maiores diferenças de temperatura em relação à situação real. A faixa de 30 a 50\%, no entanto, não acompanhou o mesmo comportamento. O CA está diretamente ligado ao aumento de superfícies e de sombreamento das áreas urbanas. Por isso, essa diferença de comportamento entre as faixas pode ser um indício de que o sombreamento gerado pela elevação das edificações (com incremento de CA entre 60 e $80 \%$ ) pode criar um sombreamento significativo e, por isso, o aumento da temperatura do ar pode não ser tão intenso quanto aquele encontrado com o incremento da faixa entre 30 e $50 \%$.

O mesmo tipo de análise foi desenvolvido para relacionar o incremento do CVU com as diferenças térmicas. Os resultados encontrados são apresentados na Figura 11.

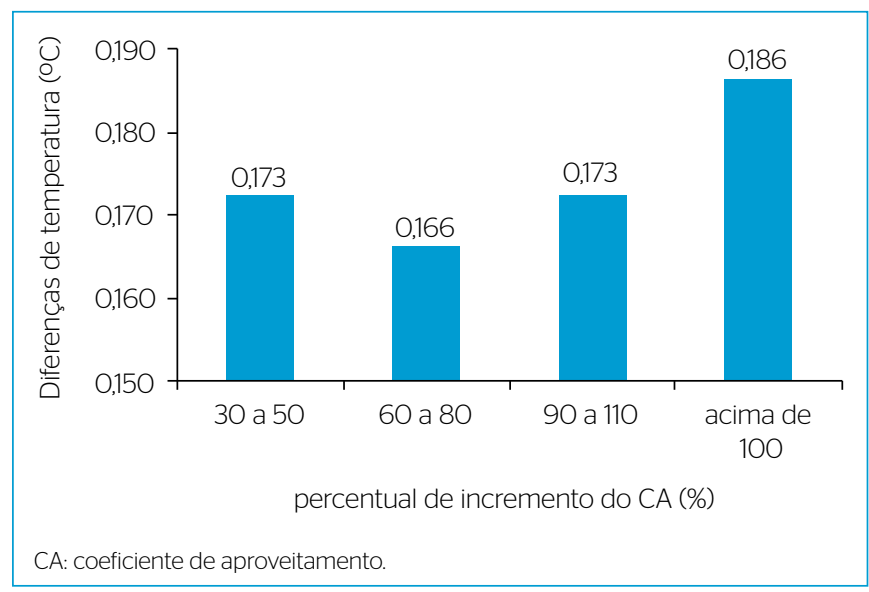

Figura 10 - Diferenças de temperaturas em função do aumento do coeficiente de aproveitamento.

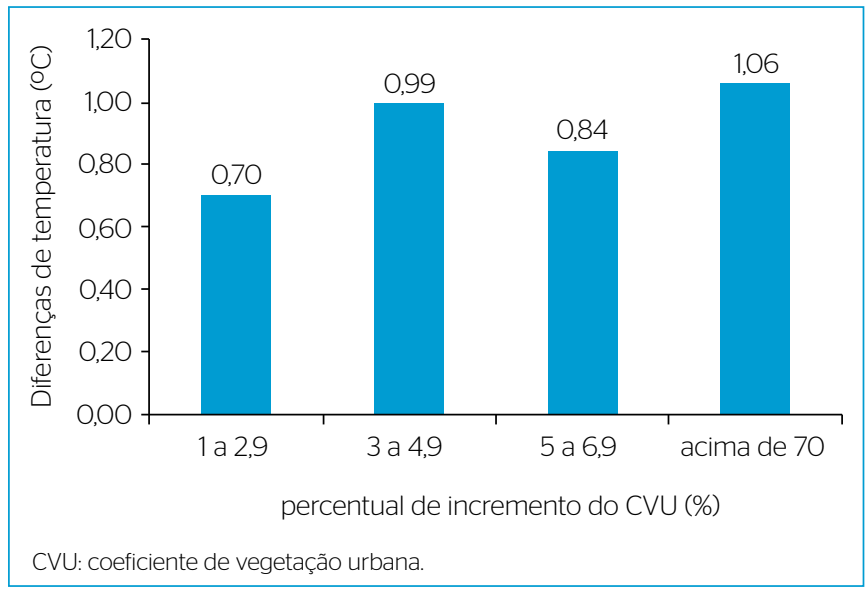

Figura 11 - Diferenças de temperaturas em função do aumento do coeficiente de vegetação urbana. 
Para o incremento do CVU, apesar de não ser verificado um comportamento linear, nota-se uma tendência de maior influência da vegetação sobre a temperatura, à medida que ocorreu um incremento na taxa de vegetação. A capacidade de resfriamento da temperatura do ar foi mais uma vez confirmada e revelou que as diferenças de temperatura do ar podem alcançar mais de $1^{\circ} \mathrm{C}$, quando $\mathrm{o}$ aumento do CVU é acima de 70\%. Para todas as faixas de incremento de CVU foram verificadas diferenças significativas, reduzindo a temperatura do ar do entorno.

\section{CONCLUSÕES}

Verificou-se que o CO tem uma leve influência sobre a temperatura do ar, enquanto o CA e o coeficiente de vegetação urbana (CVU) indicaram uma influência térmica mais significativa. Esses dois últimos indicaram tendências à redução da temperatura do ar. No caso da cobertura vegetal, esse pode ser um comportamento esperado, mas no caso do CA são necessários mais estudos que se aprofundem nos limites térmicos desse coeficiente dentro das condições climáticas específicas de cada estudo.

Como o CA está relacionado à altura das edificações, seu incremento pode trazer o sombreamento e a diminuição de temperaturas em determinadas épocas do ano. Porém também pode representar uma barreira à entrada de ventos, se a porosidade da geometria urbana for prejudicada, e consequentemente acarretar o aquecimento do entorno. Além disso, pode também significar maior armazenamento de calor pelas superfícies dos materiais construtivos. Por isso, são necessários estudos que permitam estabelecer o ponto de equilíbrio, para que esse coeficiente não dificulte o adequado balanço térmico urbano.

A cobertura vegetal urbana (CVU), entre os coeficientes estudados, foi a que apresentou maior impacto sobre a temperatura do ar no entorno. Nas simulações realizadas, as diferenças alcançadas foram de até $1^{\circ} \mathrm{C}$. Para todos os cenários estudados, a região da praça arborizada é a que apresenta menores temperaturas do ar. Além disso, esse cenário apresentou-se como o de temperaturas mais baixas.

Por outro lado, observou-se que, dentro da fração escolhida, o cenário adensado apresentou as maiores médias de temperatura em relação aos cenários real e arborizado.

Por fim, com o dinamismo apresentado pelas cidades hoje, cada vez mais a consideração do ambiente térmico urbano deve ser acatada para a maior qualidade de vida urbana. Nesse sentido, pesquisas futuras nessa área devem se preocupar com o aprofundamento de ferramentas de previsão, de forma a que os planejadores urbanos possam contar com um efetivo apoio à tomada de decisões.

\section{REFERÊNCIAS}

CALLEJAS, I.J.A.; OLIVEIRA, A.S.; SANTOS, F.M.M.; DURANTE, L.C.; NOGUEIRA, M.C.J.A. (2011) Estudo comparativo de temperatura e umidade entre meio urbano e rural. In: ENCONTRO NACIONAL DE CONFORTO NO AMBIENTE CONSTRUÍDO, 11., e ENCONTRO LATINO AMERICANO DE CONFORTO NO AMBIENTE CONSTRUÍDO, 7. Anais... Búzios. 10p.

CARFAN, A.C:; GALVANI, E.; NERY, J.T. (2009) Calibração do modelo ENVI-met: estudo do clima urbano de Ourinhos-SP. 13 p. Disponível em: <http://www.geo.ufv.br/simposio/simposio/trabalhos/trabalhos_ completos/eixo8/002.pdf>. Acesso em: 12 mar. 2013.

DUARTE, D.H.S. (2010) Variáveis urbanísticas e microclimas urbanos: modelos empírico de proposta de um indicador. Fórum Patrimônio: Ambiente Construído e Patrimônio Sustentável, Belo Horizonte, v. 3, n. 2. Disponível em: <http://www.forumpatrimonio. com.br/seer/index.php/forum_patrimonio/article/view/48/43>. Acesso em: 17 out. 2013.

HUTTNER, S.; BRUSE, M.; DOSTAL, P. (2008) Using ENVI-met to simulate the impact of global warming on the microclimate in central European cities. In: JAPANESE-GERMAN MEETING ON URBAN CLIMATOLOGY, 5. p. 307-312. Disponível em: <http://envimet.net/documents/papers/Huttner_etal_2008.pdf>. Acesso em: 16 set. 2013.
INSTITUTO BRASILEIRO DE GEOGRAFIA E ESTATISTICA (IBGE) Disponível em: <https://cidades.ibge.gov.br/brasil/sp/sao-carlos/ panorama>. Acesso em: 19 abr. 2012.

JOHANSSON, E. (2006) Influence of urban geometry on outdoor thermal comfort in a hot dry climate: a study in Fez, Morocco. Building and Environment, v. 41, p. 1326-1338. Disponível em: <http://www.sciencedirect.com/science/article/ pii/S0360132305001952>. Acesso em: 10 nov. 2012. https://doi. org/10.1016/j.buildenv.2005.05.022

KATZSCHNER, L; THORSSON, S. (2009) Microclimatic investigations as tool for urban design. In: INTERNATIONAL CONFERENCE ON URBAN CLIMATE, 7., Yokohama, Japão. 4p.

MELO, J.D.; BARBIRATO, G.M. (2011) Informações para o planejamento a partir da caracterização climática urbana: Estudo em Maceió-AL. In: ENCONTRO NACIONAL DE CONFORTO NO AMBIENTE CONSTRUÍDO, 11.; ENCONTRO LATINO AMERICANO DE CONFORTO NO AMBIENTE CONSTRuÍdo, 7. Anais... Búzios. 10p.

MENDONÇA, A. B. D.; SURIANO, M. T.; SOUZA, L. C. L.; VIVIANI, E. (2013) Classes de quadras urbanas determinadas pelos níveis de ruídos. Revista Brasileira de Gestão Urbana, v. 5, n. 2, p 63-77. 
MINELLA, F.C.O.; RASIA, F.B.C.; KRÜGER, E.L. (2011) Impactos microclimáticos do desenho urbano: Estudos realizados em Curitiba. Departamento de Geografia da UFPR. Curitiba. Revista RA 'EGA, v. 21, p. 298-336.

MONTEIRO, C.A.F. (1976) O clima e a organização do espaço no Estado de São Paulo: problemas e perspectivas. Tese (Doutorado) Universidade de São Paulo, São Paulo.

NAKATA, C.M. (2010) O comportamento do pedestre e ambiente térmico urbano. 132f. Dissertação (Mestrado) - Faculdade de Arquitetura, Artes e Comunicação, Universidade Estadual Paulista “Júlio de Mesquita Filho", Bauru.

NAKATA, C.M.; SOUZA, L.C.C. (2013) A review of methods of urban climate representation and simulation. In: INTERNATIONAL CONFERENCE ON URBAN CLIMATE AND HISTORY OF METEOROLOGY. Anais... 2013. 9p.

OH, E.J.; LEE, H. W.; KONDO, A.; KAGA, A.; YAMAGUSHI, K. (2OO4) Micro-climate prediction in a residential development region using a numerical model. Ecological Modelling, v. 177, p. 283-295. Disponível em: <https://www.sciencedirect.com/science/article/pii/ S0304380004001401>

OKE, T.R. (1982) The energetic basis of the urban heat island. Quarterly Journal of the Royal Meteorological Society, v. 108, n. 455, p. 1-24. https://doi.org/10.1002/qj.49710845502
PREFEITURA MUNICIPAL DE SÃO CARLOS. Dados da cidade. Disponível em: <http://www.saocarlos.sp.gov.br/index.php/conhecasao-carlos/115442-dados-da-cidade-geografico-e-demografico.html> Acesso em: 12 dez. 2012.

ROCHA, L.M.V.; SOUZA, L.C.L.; CASTILHO, F.J.V. (2011) Ocupação do solo e ilha de calor noturna em avenidas marginais a um córrego urbano. Ambiente Construido, v. 11, n. 3, p. 161-175. http://dx.doi. org/10.1590/\$1678-86212011000300012

SÃO CARLOS. (2005) Leino 13.691, de 25 de novembro de 2005. Institui o Plano Diretor do Município de São Carlos e dá outras providências. Seção 1. 69p. Disponível em: <http://www.saocarlos.sp.gov.br/images/ stories/pdf/Lei_13691_05_Plano_Diretor.pdf>. Acesso em: 24 out. 2012

SOUZA, H.M. (2010) Avaliação do desempenho térmico nos microclimas das praças: Piedade e Visconde de Cayrú, Salvador. 203f. Dissertação (Mestrado em Engenharia Ambiental Urbana) Universidade Federal da Bahia.

SOUZA, L.C.L. (1996) Influência da geometria urbana na temperatura do ar ao nivel do pedestre. 100f. Tese (Doutorado em Ciências da Engenharia Ambiental) - Escola de Engenharia de São Carlos, Universidade de São Paulo, São Carlos.

UNGER, J.; PONCRÀZ, R. (2008) Urban climate research in Hungary. Urban Climate News. Quarterly Newslerrer of the IAUC. International Association for Urban Climate, n. 28. 26p. Disponível em: <www.urban-climate.org>. Acesso em: 9 dez. 2012. 